\title{
Robot vs. Human Teacher: Instruction in the Digital Age for ESL Learners
}

\author{
Virginia H. Y. Kwok ${ }^{1,2,3}$ \\ ${ }^{1}$ Hong Kong Baptist University, Hong Kong, China \\ ${ }^{2}$ The University of Auckland, New Zealand \\ ${ }^{3}$ The Chinese University of Hong Kong, Hong Kong, China \\ Correspondence: Virginia H. Y. Kwok, Department of Education Studies, Hong Kong Baptist University, Hong \\ Kong, China. E-mail: hon_yuen@hotmail.com
}

Received: February 17, 2015 Accepted: May 19, 2015 Online Published: June 29, 2015

doi:10.5539/elt.v8n7p157 URL: http://dx.doi.org/10.5539/elt.v8n7p157

\begin{abstract}
Living in the twenty-first century, life unplugged seems impossible without the Internet, mobile phones, i-products or other types of electronic gadgets for long. While language educators are overwhelmingly occupied with investigating the impact of computers and mobile learning, here is a call to address the value of face-to-face instruction in second language education. The key function of second language learning is to interact with one another in the target language. Younger generations are, however, becoming indulged in and even addicted to the technological tools without significant improvement in language competency and communication skills when compared with predecessors who have less accessibility of such tools that are so prevalent nowadays. The current empirical study explores the possibility of 'avatar teacher', alternatives to over-reliance on online tools, electronic gadgets and robot teachers, and limitations of technology on ESL education. Recommendations of innovative ways to engage learners with controlled amount of technology are made to language education professionals.
\end{abstract}

Keywords: English as a Second Language (ESL) learners, human teacher, limitations, robot teacher, technology

\section{Introduction}

With the tech-savvy young generation fully occupied by technological tools and gadgets in their daily life, educators are pondering the impact it has on language learning. Effective language teaching and learning needs live communication face-to-face (Smith, 1998, p. 44). But some teachers think an avatar teacher not only possesses infinite patience and wisdom, but also have qualities highly valued by students: wit, hotness and easiness, and for school authorities: rigor, professionalism, and high standards. Everybody would be happy to have such teachers around. For students, the quest for favorable impression in the classroom: to be thought of as quick, responsive, and brilliant is also intense and sincere. However, the ideal world is built on myth rather than reality, which means the truth of human limitations and weaknesses have to be dealt with at some points if true learning needs to be attained.

However, some still contend that a robot teacher is indifferent to class size and reacts on an individual basis to each student, they could 'teach' many students at one go while saving time of human teachers to play the monitoring role and other tasks. So what is the role of face-to-face instruction by a human teacher in the digital age for ESL learners when online education and avatar teaching are evolving? With this question in mind, this paper attempts to address the issues and shed some light on pedagogical practice for language education professionals.

\section{Literature Review}

Several studies in recent years have compared face-to-face instruction by human teachers with online delivery methods and robot teaching. Marchand and Gutierrez (2012) examined the role of emotion in the learning process and compared online and face-to-face learning settings among graduate students. Results demonstrated that online students tend to face greater level of anxiety and frustration and these could better be alleviated by providing advice on improvement of learning strategies face-to-face. 
Besides, Esani (2010)'s study found a lack of social presence in online learning community sacrifices education quality even though it may be more efficient. Cherry's (2010) research documented blended learning on K-12 campuses and showed that when educators harness the power of the Internet to create more efficient, democratic learning experiences and meet the needs of the Net Generation, still face-to-face learning is required to an improved classroom climate.

Chang, Lee, Chao, Wang, and Chen's (2010) study focused on using humanoid robots as instructional tools for teaching a second language in a primary school. This shows that while robot teachers may encourage children to practice language skills naturally due to the anthropomorphic characteristics of the robot and thus lowered student anxiety. However, insufficient teacher training and guidance may cause the robot to become nothing more than a distracting toy in the classroom. High student motivation following the initial introduction of the robot decays rapidly. The inability of robots to adequately portray emotions hinders the extent to which they could be used in contexts such as storytelling or drama scenario.

Second language learners' learning situations are varying in nature. It is dynamic and ever changing. Due to limitations of computer's artificial intelligence, computer technology is unable to deal with learners' unexpected problems and respond to learners' questions immediately as human teachers do. Some students are not comfortable learning with computers so they often make mistakes. Given the fact that computers cannot conduct open ended dialogues and cannot give feedback to open ended questions (Seileek, Farhan, \& Sa'aleek, 2012), these problems can demonstrate that while technology could have much to offer for the new generation of learners for its high efficiency in delivering materials and processing data, lacking emotions and social presence, falling motivation after the initial excitement of a robot teacher, and difficulties of addressing the complex learner needs and inability to answer open-ended question in real time may result in limitations in the extent to which robot teacher and online delivery methods could enhance ESL learners' learning process.

Wuensch (2008) also pointed out the advantages of face-to-face instruction over online methods. These include: i) natural social and spatial awareness in face-to-face classrooms. Students observe the reactions of other students and their instructors. ii) The physical arrangement of the face-to-face classroom is better for interaction between students and instructors as compared with online course delivery systems in which the interface is limited to the computer monitor. iii) Interaction with classmates is easier in the traditional classroom as both social and intellectual interactions are immediate, dynamic, and more efficient than with the online education environment. iv) In face-to-face education, the facial expressions and body language of students provide a feedback mechanism for instructors. Instructors can easily understand when students' attention levels decrease from their body language and facial expressions. This is not currently possible with online education or robot teacher. v) Face-to-face communication is faster and more efficient than online communication since a considerable amount of time and effort may be spent in decoding and creating email messages, chat logs, and other textual information. The communication time in online education can be $29 \%$ greater than face-to-face learning (Kennedy, 2002). In a physical classroom setting, instructors can easily channel their students' attention to a certain element of the course material. In the typical online education setting, instructors' messages tend to get lost among other textual material and may not be noticed by students. vi) The student assessment process is usually perceived to be more reliable in a traditional face-to-face instruction. In online education, there is a geographical distance between students and instructors; therefore, it is often difficult or even impossible for instructors to control the testing environment. This will affect validity and reliability of the test and its results.

Furthermore, student-instructor interactions can enhance student retention, self-motivation, and pass rates. Therefore we can see that even some learners prefer to rely on technology alone for language learning, the advantages of having face-to-face instruction and interaction by human teachers still outweigh the disadvantages.

Finally, language educators certainly do not want to produce students who 'maybe technologically sophisticated yet rhetorically illiterate', aware of the creative potential of online world but naïve to the dangers, and with only a passive sense of how effective texts work to achieve a purpose (Handa, 2004). With Japan's first robot teacher, a 'humanoid' that performs roll call as well as set tasks from textbooks and has been test-piloted in a Tokyo primary school, the robot teacher is one example of how technology may affect the definition of the teaching professional (Lamberti, 2011, p. 41). But what human teachers can do that a robot teacher cannot in a language classroom? When teachers embrace opportunities to better understand who they are and to clarify who they want to be, and how they are to train their students, then it will be clearer when they are involved in the twenty-first century ESL language education.

\section{The Current Study}

'Robot vs. Human Teacher' - to touch or not to touch: this refers to the question of whether robots and online 
tools, technological gadgets and digital media should be used in second language education to replace human teachers' face-to-face instruction entirely. Without doubt, iPhones, iPads, iPods, tablet computers, laptops, the Internet and other technological gadgets are becoming part of necessities of modern people's lives. It has also transformed the way people learn English. The question is: whether these tools can help to improve ESL students' learning process or are there limitations to what they can do? What would learners prefer when they have the option of having a robot teacher or a human teacher in the classroom? And what can human teachers do that robot teachers would not teach them? The current study aims to answer these questions.

\subsection{Methodology}

A pilot study had been carried out among thirteen secondary school students aged between 12 and 17 in Hong Kong. They were asked to give answers to the following question in a questionnaire: "As an ESL learner, would you prefer to be taught by a Real (Human) or a 'Robot Teacher'? Why?" Students were asked to give reason for their answer and more than one reason was acceptable. Their written answers were collected and analyzed.

\subsection{Findings and Discussion}

The results of the findings are presented below.

Seven of the thirteen students preferred to be taught by a real teacher while six of them preferred to be taught by a robot teacher. Reason(s) for the answer:

Students who preferred a human teacher quoted the following reasons:

1) There will be dynamic interactions with students.

2) There will be more variety in the intonation when a real teacher interacts with the students.

3) A real teacher will care about your feelings

4) A robot teacher doesn't have feelings

5) A robot teacher doesn't know how to change the teaching methods to accommodate the needs of the students

6) A robot teacher doesn't have feelings and so will make the lesson boring

7) A robot teacher won't punish students or correct their mistakes

8) A robot teacher might sound boring

9) It is better to ask a real person questions rather than asking a robot as robots have no feelings and it will be boring to interact with a machine.

Students who preferred a robot teacher, however, stated the following reasons:

1) We can have fun with a robot teacher.

2) We can change the program in a robot teacher to suit our needs.

3) A robot teacher won't punish us and let us have our way.

4) A robot teacher will listen to us and won't punish us.

5) A robot teacher will not react in angry ways when students are talking in class as robots have no feelings.

6) A robot teacher won't feel angry and students can hit the robot teacher without getting punished.

7) A robot teacher won't shout at students as robots have no feelings.

It is found that slightly more students prefer a human teacher to a robot teacher for the main reason that human possesses and expresses emotions while this characteristic is absent in robot teachers. Interestingly, those who chose robot teacher over human ones also gave the same reason in that robots do not have emotions and so they will not get angry when students misbehave and thus students will not be punished by robot teachers.

We can see from the findings that 'a robot teacher' may sound appealing but there is certainly the significant role of face-to-face instruction by a human teacher in ESL learning. A robot teacher may not be user-friendly and technological gadgets may discourage some users as they lack the ability to communicate emotions effectively.

Also, with face-to-face instruction and interaction, human teachers who know their students' complex needs could better provide learner support at the cognitive, affective and systemic levels. a) cognitive refers to tutoring, study groups and centers, study and exam skills seminars, 1:1 assistance; b) affective refers to guidance and advisory services such as motivational counselling, residential schools and peer contact; c) systemic refers to enquiry and admission services, course or academic information and guidance (Moore \& Kearsley, 1996, Harms et al., 2006) 
Limitations of my exploratory research are that the sample size is only thirteen secondary school students in one city. If the study were carried out in primary school or among adult learners in another city or country, the results might have been different and this may be the objective for further research. Also, the students surveyed consisted of both boys and girls but their preference and reasons behind those preferences have not been analyzed based on the gender of the sample population. Further study may look into such differences. Finally, students chosen for the study were of high academic ability and the research findings may reveal similar or greatly distinct preferences and opinions when students of weaker ability students were in the sample population. Future research might be conducted to find out the results in these aspects.

It has been found in the current study that among a group of high ability secondary school students in Hong Kong consisting of boys and girls, a slightly greater proportion of students prefer to be taught by human teachers in the English lessons than by robot teachers. Reasons for higher preference for human teachers as compared to robot teachers range from having more dynamic interaction with human teachers to human teachers showing emotions, care and concern for students. Those students who prefer robot teachers also cite the reasons that they will not get punished if they misbehave during the English lessons as robots do not have feelings. While emotional intelligence of human teachers and development of such characteristic in robot teachers might be of interest for researchers in future study, it can be seen that emotions do play a significant role in English language teaching among young people. Interaction with human teachers takes precedence over that of robots as students have the perception that questions will be answered in more empathetic and humane manners with human teachers than doing so with machines.

\section{Pedagogical Implications}

If the findings indicate that face-to-face instruction by human teachers is important in the digital age for ESL learners, then what are the limitations of technology and alternatives to over-reliance on online tools and robot teaching in ESL education?

\subsection{Limitations of Technology}

\subsubsection{Lack of Instant Feedback, Technical Support and Emotional Attributes}

It is difficult to carry on a stimulating teacher-class discussion when spontaneity is altered by technical requirements and distance in the online setting, and the existence of time lag between the online learner who receives and reads the message means the instructor must be available to them after normal office hours. This "non-stop" nature of online learning along with the need to provide constant feedback and clarification may be time-consuming and labor intensive for the instructor to review and respond to. Furthermore, plenty of technical support is needed for close monitoring to keep the flow of ideas presented in online environment to be well-maintained. And facial gestures and expressions of human teachers in the face-to-face setting make real time feedback more efficient and effective.

\subsubsection{Plagiarism and Communication Ability in the Real World}

The problem of plagiarism and electronic vandalism arisen from using new technology in language education should be addressed and discouraged by setting suitable educational computing systems. Also, language teachers would like to see students being able to communicate in English in the real world rather than in the virtual world alone. So face-to-face interaction and training become an indispensable part of ESL education.

\subsection{Alternatives to Over-Reliance on Technology in ESL Education}

\subsubsection{Address Various but also Universal Needs of Different Language Learners-To Connect with One Another}

In ESL learning and teaching, the connection and feeling of being part of a learning community is somewhat lacking in online education and it is not unusual for an online student to feel isolated. In the face-to-face setting, through classroom discussions, language laboratory exercises, oral and written examinations, instructors have regular contact with students and are able to assess their prior learning and level of cognitive knowledge in every class. They can obtain unobtrusive visual cues from their students to enhance their delivery. For example, a quick glance reveals who is attentively taking notes, pondering a difficult concept, or preparing to make a comment. The student who is frustrated, confused, tired or bored is equally evident. The attentive instructor consciously and subconsciously receives and analyzes these visual cues and adjusts the course delivery to meet needs of the class during a particular lesson. It can be done more easily with face-to-face instruction.

\subsubsection{Motivate with Rewards and Positive Reinforcements - In Physical Form and Encourage Goal Setting}

Students who complete the ESL course and receive a distinction in the end of year examination or a public examination could enter a raffle, with a certain number of them to receive a prize (e.g. a memory stick, book 
coupon or even an iPod depending on the budget that is available at the institute) to motivate students to set their goal and attain them the best that they could. Teachers can encourage goal setting and affirmation of good results when learners make progress. Besides, students can be encouraged to set up short-term, interim and long-term goals and teachers can encourage them to put in their best effort to achieve them.

\section{Recommendations}

After looking at the findings and implications of the study, innovative ways to engage learners with controlled amount of technology are recommended. This can be done in a number of ways.

\subsection{Motivation}

Use technology and digital media as starting point and motivational tools

Teachers can show video project of students on Youtube, upload good essays onto Facebook or Twitter, combine with experiential learning such as using mobile phones to search for the 'Wanted Person' by giving instruction in the target language to locate the missing person in a class activity.

It is well-known that computer-assisted language tools can be convenient, efficient, challenging, fun and rewarding. Materials delivered online or through other technological gadgets also provide learners the opportunity to work with new and emerging cutting edge technologies (Coppola, 2002). The instructor can create interactive learning tools for teaching challenging concepts, which is more interesting and exciting for the learner than using still pictures or verbiage. The tools can be used as motivational tools to stimulate students' learning interest in a face-to-face lecture.

Therefore using IT as a tool (as opposed to using it as a teacher) can encourage creativity by asking questions with open answers, foster high level IT skills, develop intrinsic motivation in learners, leading learners to be active, creating multimedia and web pages, checks and corrects grammar as well as spelling mistakes, enable learners to acquire skills and knowledge and creating the future (Wainewright, 1998, p. 109).

\subsection{Engagement}

\section{Engage learners with relevant, useful and valuable materials}

Language educators can select materials that are relevant to current examination syllabuses, useful to meet the needs of future job demands and valuable to improve the quality of daily life or character building through learner-centered curriculum and challenging tasks. Technology and digital media could be used as updated tools and sources of information. Use of eternally true and relevant materials could maintain high moral standard and values among learners. In this way, learners can gain a higher level of motivation for learning and thus a greater sense of fulfillment and achievement.

The idea is to motivate and engage learners through tasks that require adaptability and managing complexity, self-direction (encourage students to explore and discover as they learn best through exploration and direct experience, we can think of how to expand their space and opportunities for learning), curiosity, creativity, risk-taking, higher-order thinking and sound reasoning (Warschauer, 2006, pp. 135-136). Supported these learning tasks by technology and use 'blended classroom and experiential learning methods' to teach a second language will prove more effective and beneficial to ESL learners.

\section{Conclusion}

With the rapid development of the Internet, different technological tools and even robot teaching, more and more second language teachers and learners are exploring those digital media and gadgets for ESL education. Besides being powerful and stimulating aids, computers and new technologies offer great potential for language learning. Teachers need to know how technology can assist learners at various levels of ability and provide suitable support to learners for successful second language acquisition so they are able to communicate in the real world.

As far as digital media is concerned, 'To touch, or not to touch, that is the question', it seems justifiable that there is the resistance of using online teaching methods, technological gadgets and robot teachers quoting technical difficulties and limitations as an excuse, the love of interaction with a human teacher possessing emotions over a technological one in physical environment, the inaccessibility of websites due to updates and removing of webpages when you need them most, thus making it reasonable not to incorporate technology when teaching the language course's content (Craton, 2011). But some argued that students may be more engaged in the learning process through the use of computers, the Internet, other digital devices and avatar teacher to develop their critical thinking, entrepreneurship and innovation essential for twenty-first century learners' success. Yet these same tools may also exacerbate the problem of distractions from attention to intended 
teaching content for lack of proper organization in the school (Warschauer, 2006, p. 133) or classroom discipline management by robot teachers. Technology alone cannot alter these problems.

To conclude, even though technology itself is a powerful tool, how it would be used and to what extent it could be used will require the wisdom, knowledge, experience and professional judgment of teachers when conducting their language classes in the twenty-first century's digital age. Technology may redefine the teaching professional (Lamberti, 2011), but controlled amount of technology rather than over-reliance would be the appropriate way to go in motivating and engaging learners. And with more advanced technology, there will be a greater value of face-to-face interaction as human touch could hardly be replaced by robots or machines which lack emotional attributes. The basic needs of human to connect and interact have not changed: to learn in ways that are creative, interactive, exciting and relevant to one's needs. Whether it is past, present or future, the role of face-to-face instruction and interaction between human teachers and learners will continue to play a significant role in ESL education in the generations to come as ultimately it is those human dimensions that count.

\section{Note}

This is a revised version of the paper presented at the $19^{\text {th }}$ AFMLTA National Conference with the theme, 'Inspire, Innovate, Interact', Australian National University, Canberra, Australia, July, 2013.

\section{References}

Chang, C.-W., Lee, J.-H., Chao, P.-Y., Wang, C.-Y., \& Chen, G.-D. (2010). Exploring the possibility of using humanoid robots as instructional tools for teaching a second language in primary school. International Forum of Educational Technology \& Society, 13(2), 13-24. Retrieved from http://www.ifets.info/journals/ 13_2/2.pdf

Cherry, L. D. (2010). Blended learning: An examination of online learning's impact on face-to-face instruction in high school classrooms (PhD Thesis, Walden University). Retrieved from http://search.proquest.com/ docview/851224909? accountid $=10371$

Coppola, N., Hiltz, S., \& Rotter, N. (2002). Becoming a virtual professor: Pedagogical roles and asynchronous learning networks. Journal of Management Information Systems, 18(4), 169-189. http://www.jstor.org/ stable/40398548

Craton, L. E. (2011). To E-read or Not to e-read: Rethinking resistance to digital texts in the literature classroom. In L. R. Davis, \& S. Linda (Eds.), Teachers as avatars: English studies in the digital age (pp. 115-126). New York: Hampton Press, Inc.

Esani, M. (2010). Moving from face-to-face to online teaching. Clinical Laboratory Science, 23(3), 187-190. Retrieved from http://www.freepatentsonline.com/article/Clinical-Laboratory-Science/277345336.html

Foster, A. (2007). Professor Avatar. The Chronicle of Higher Education, 54(4). Retrieved from http://chronicle.com/

Garrison, D., Anderson, T., \& Archer, W. (2001). Critical thinking, cognitive presence and computer conferencing in distance education. American Journal of Distance Education, 15, 7-23. http://dx.doi.org/10.1080/08923640109527071

Handa, C. (2004). Introduction: Placing the visual in the writing classroom. Visual rhetoric in a digital world: A critical sourcebook (pp. 1-5). Boston: Bedford.

Harms, C., Niederhauser, D., Davis, N., Roblyer, M. D., \& Gilbert, S. (2006). Educating educators for virtual schooling: Communicating roles and responsibilities. Electronic Journal of Communication, 16(1/2), 17-24. Retrieved from http://www.cios.org/EJCPUBLIC/016/1/01611.HTML

Kennedy, D. M. (2002). Dimensions of distance: A comparison of classroom education and distance education. Nurse Education Today, 22(5), 409-416.

Lamberti, A. P. (2011). Remediating professionalization: Twenty-first century English Studies. In L. R. Davis, \& L. Stewart (Eds.), Teachers as avatars: English studies in the digital age (pp. 239-252). New York: Hampton Press, Inc.

Larson, D. K., \& Sung, C.-H. (2009). Comparing student performance: online versus blended versus face-to-face. Journal of Asynchronous Learning Networks, 13(1), 31-42. Retrieved from http://files.eric.ed.gov/fulltext/ EJ837556.pdf

Marchand, G. C., \& Gutierrez, A. P. (2012). The role of emotion in the learning process: comparisons between online and face-to-face learning settings. Internet and Higher Education. Elsevier, Elsevier Science Inc. 
Retrieved from http://www.academia.edu/4176652/The_role_of_emotion_in_the_learning_process_ Comparisons_between_online_and_face-to-face_learning_settings

Moore, M. G., \& Kearsley, G. (1996). Distance education: A systems view. Belmont: Wadsworth Publishing Company.

Rovai, A., Ponton, M., Wighhting, M., \& Baker, J. (2007). A comparative analysis of student motivation in traditional classroom and e-learning courses. International Journal on E-Learning, 6(3), 413-420. Retrieved from http://www.editlib.org/index.cfm?fuseaction=Reader.ViewAbstract\&paper_id=20022

Seileek, A., Farhan, A., \& Sa'aleek, A. O. A. (2012). Computer assisted language learning: Merits and demerits. Language in India, 12(4), 31-44. Retrieved from http://www.languageinindia.com/april2012/v12i4april 2012.pdf

Smith, M. (1998). An overview of current uses of technology in language teaching in Australian secondary schools. In G. Poedjosoedarmo, \& J. I. Lee (Eds.), Information Technology in English Language Learning. Conference Proceedings. Division of English Language and Applied Linguistics (pp. 44-62). Singapore: National Institute of Education.

Wainewright, M. (1998). Using IT as a tool to support \& develop language skills. In G. Poedjosoedarmo, \& J. I. Lee (Eds.), Information Technology in English Language Learning. Conference Proceedings. Division of English Language and Applied Linguistics (pp. 104-111). Singapore: National Institute of Education.

Warschauer, M. (2006). Laptops and literacy: Learning in the wireless classroom. New York: Teachers College Press.

Wuensch, K. L., Aziz, S., Ozan, E., Kishore, M., \& Tabrizi, M. H. N. (2008). Pedagogical characteristics of online \& face-to-face classes. International Journal on E-Learning, 7(3), 523-532. Chesapeake, VA: Association for the Advancement of Computing in Education (AACE). Retrieved from http://www.editlib.org/index.cfm?CFID=6640380\&CFTOKEN=82571309\&fuseaction=Reader.ViewAbstra ct\&paper_id $=24201$

\section{Copyrights}

Copyright for this article is retained by the author(s), with first publication rights granted to the journal.

This is an open-access article distributed under the terms and conditions of the Creative Commons Attribution license (http://creativecommons.org/licenses/by/3.0/). 